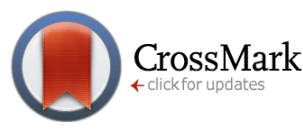

*For correspondence:

pvphuc@hcmuns.edu.vn

Competing interests: The authors declare that no competing interests exist.

Received: 11 October 2016 Accepted: 01 December 2016 Published: 21 December 2016

Copyright The Author(s) 2016. This article is published with open access by BioMedPress (BMP).

This article is distributed under the terms of the Creative Commons Attribution License (CC-BY 4.0) which permits any use, distribution, and reproduction in any medium, provided the original author(s) and the source are credited.

\section{Adipose tissue derived stromal vascular fraction transplantation can recover spinal cord injury in mice}

\author{
Hau Thi-My Lam ${ }^{1}$, Minh Nguyen-Thu Tran', Khoa Anh Bui ${ }^{1}$, Thao Thi- \\ Thu Le ${ }^{1}$, Khanh Hong-Thien Bui ${ }^{2}$, Ngoc Kim Phan1, Phuc Van Pham ${ }^{1, *}$ (D)
}

\author{
${ }^{1}$ Laboratory of Stem Cell Research and Application, University of Science, Vietnam \\ National University, Ho Chi Minh City, Viet Nam \\ 2University of Medical Center, Ho Chi Minh University of Medicine and Pharmacy, 215 \\ Hong Bang, District 5, Ho Chi Minh City, Vietnam
}

\section{Abstract}

Introduction: Stem cell therapy is one of the most promising therapies for degenerative diseases and related injuries. Adipose tissue derived stem cells (ADSCs) exhibit some particular properties such as high production of paracrine factors. Indeed, ADSCs have been successfully used to treat diseases, including osteoarthritis, diabetic ulcer, etc. Methods: In this study, ADSCs were used to treat spinal cord injury $(\mathrm{SCl})$ in a mouse model. Non-expanded ADSCs, from stromal vascular fractions (SVFs) isolated from both autologous and allogeneic adipose tissues, were injected into injured sites of mice at a specified dose. The $\mathrm{SCl}$ mouse model were generated by transection of spinal cord at vertebrae T8 - T10. After 1 week of transection, mice exhibiting completed $\mathrm{SCl}$ were divided into 4 groups: group 1 was control (mice without any treatment), group 2 was placebo (mice treated with platelet rich plasma (PRP)), group 3 was allogeneic SVF transplantation (mice treated with allogeneic SVFs), and group 4 was autologous SVF transplantation (mice treated with autologous SVFs). For the treatment groups, mice were transplanted with $20 \mu \mathrm{L}$ of activated PRP or/and with $10^{6}$ cells of SVF (allogeneic or autologous) into the injured position through laminectomy. The recovery of $\mathrm{SCl}$ was evaluated by locomotor test, sensory test and sensory-motor test at 5 weeks after transplantation. The histology of the spinal cord also was checked after 5 weeks. Results: The results showed that in all groups with PRP injected with or without SVFs, the inflammation was efficiently controlled. The glial scar as well as myelin defragmentation were clearly reduced. However, a significant improvement of BBB score was only recorded in mice transplanted with autologous SVFs. Conclusion: The results of our study show that autologous SVF transplantation in combination with PRP can be a promising therapy for $\mathrm{SCl}$. 


\section{Keywords}

Adipose derived stem cells, Mesenchymal stem cells, Spinal cord injury, Stem cell therapy, Stromal vascular fraction

\section{Introduction}

The spinal cord is an organ within the nervous system with limited ability to regenerate after injury. Mechanical action would affect the internal structure and blood flow interruption could destroy nerve and glial cells. Damaged cells respond by releasing neurotoxic factors, producing cleaved axonal myelin, and inducing greater cell death. The inflammatory response starts to increase and leukocytes are mobilized to the site of damage. Astrocytes and fibroblasts produce glial scars. All of the above impede spinal cord recovery (Blight, 2000; Donnelly and Popovich, 2008).

Many therapies have been administered- some immediately and some long after $\mathrm{SCl}$. There have been the use of nervous growth factors, neuro-protective factors, and scaffolds possessing similar spinal cord structures (Carballo-Molina and Velasco, 2015; Macaya and Spector, 2012; Straley et al., 2010); however, none have to date yielded expected results. Progress in transplantation of neural stem cells (NSC) from pregnant/adult brain or spinal cord, embryonic stem cells (ESCs), and induced pluripotent stem cells (iPSCs) has brought many hopes for patients with $\mathrm{SCl}$.

Adipose-derived stem cells (ADSCs) is a new type of autologous cells with many outstanding features, which include higher attainable cell number, reduced invasive capacity and lower immunogenicity (Nakagami et al., 2006; Safford et al., 2004). Compared to transplantation of bone marrow stem cells (BMSCs), which has been widely used, ADSCs are also advantageous in that they show similar uniform characteristics (in morphology, proliferation, differentiation potential and expression of various surface molecules). Nowadays, several studies have aimed to differentiate ADSCs into Schwann cells, which are important for myelinating axons in the spinal cord. Moreover, ADSC transplantations have been evaluated in a SCl mouse model (Jang et al., 2010; Jiang et al., 2008; Kingham et al., 2007; Zaminy et al., 2013; Zhang et al., 2009).

The aim of this study was to evaluate the effects of stromal vascular fraction (SVF) transplantation on spinal cord regeneration in a mouse model of spinal cord injury. 


\section{Materials-Methods}

\section{Spinal cord injury (SCl) mouse model}

Non-disease mice (8-10 weeks of age, 30-40 $\mathrm{g}$ in weight) were used in this study. Mice were anesthetized, fixed and underwent laminectomy on the back-lumbar. The $\mathrm{SCl}$ mouse model was generated by cutting the spinal cord (transection) at vertebrae T8-T10 to induce damage. Care after surgery included sutures, antiseptics, feeding, and antibiotic injections (penicillin dose of $5 \mathrm{mg} / \mathrm{kg} / \mathrm{mouse} /$ day). All manipulations were approved by the local ethical committee for animal use.

\section{Stromal vascular fraction extraction from adipose tissues}

One gram of fat tissue was collected through surgery and washed with PBS supplemented with antibiotics. The SVF was then extracted using a commercial ADSC extraction kit (Geneworld Ltd., HCM, VN). Briefly, the fat tissue was mixed with SuperExtract via gentle mixing for $5 \mathrm{~min}$ at room temperature and $50 \mathrm{~min}$ at $37^{\circ} \mathrm{C}$. After $30 \mathrm{~min}$, the digested fat was centrifuged at $2500 \mathrm{rpm}$ for $5 \mathrm{~min}$ to obtain the pellet. Next, the pellet was resuspended and filtered through an 70$\mu \mathrm{m}$ filter to collect single cells. The single-cell suspension was diluted with platelet-rich plasma (PRP) to obtain a density of $10^{8}$ cells $/ \mathrm{mL}$. The PRP was prepared from human umbilical cord blood according to a previously published protocol (Van Pham et al., 2013).

The SVFs were evaluated for presence of ADSCs and cell survival rate. The presence and percentage of ADSCs in SVFs was evaluated by flow cytometry based on expression of these markers: CD44, CD73 and CD90. Cell survival rate was evaluated based on 7-AAD dye staining and analyzed by flow cytometry. Non-expanded ADSCs, from SVFs isolated from both autologous and allogeneic adipose tissues, were used for subsequent transplantation studies.

\section{Transplantation and recovery assessment}

One week after spinal cord damage induction, mice with complete $\mathrm{SCl}$ were divided into 4 treatment groups (15 mice per group): Group 1 (control, i.e. untreated mice), group 2 (placebo, i.e. mice treated with PRP), group 3 (mice receiving $20 \mu \mathrm{L}$ of activated PRP containing $10^{6}$ allogeneic SVFs at the injury position via laminectomy), and group 4 (mice receiving $20 \mu \mathrm{L}$ of activated PRP containing $10^{6}$ autologous SVFs at the injury position via laminectomy).

To evaluate the damage level and recovery of the spinal cord injury in our mouse model, the following tests were conducted at 5 weeks post transplantation: locomotor test according to the BBB scale (Barros Filho and Molina, 2008; Basso et al., 1995), sensory test (Gale et al., 1985), and a sensory-motor test (Behrmann et al., 1992). All tests were conducted each week, for 4-5 weeks. 
According to several recent studies (Ankeny et al., 2009; Donnelly and Popovich, 2008), changes in leukocytes in the mouse models have greatly affected their ability to recover. Therefore, changes in the percentage of total leukocytes were assessed each week. The structure/histology of the spinal cord was also assessed, via HE staining, at 5 weeks after transplantation.

\section{Existence of transplanted cells}

Male SVF cells were isolated and transplanted into female recipient mice. The existence of grafted cell can be evaluated by using PCR method for spinal cord DNA extraction with SRY specific primers that only exist in the male cells.

\section{Statistic analysis}

Data were analyzed by GraphPad Prism 5 software, using 2 way ANOVA analysis followed by Bonferroni post-tests to assess differences between experiment groups; $p<0.05$ was considered statistically significant.

\section{Results}

\section{Adipose tissue derived cells}

Both autologous and allogeneic adipose tissues were used to isolate SVF cells. The results showed that there were $(1.31 \pm 0.08) * 10^{6} \mathrm{SVF}$ cells per $1 \mathrm{gram}$ of fat with $90.87 \pm 1.01 \%$ live cells. To determine the existence of mesenchymal stem cells in SVFs, total cells were analyzed for expression of CD44, CD73 and CD90. The results showed that approximately $63.26 \pm 2.02 \%$ of the cells stained positive for both CD44, CD73 and CD90 markers.

\section{Survival rate}

In all the groups, more than $50 \%$ of mice died after 5 wks. The group with the highest survival rate was the group which received autologous SVF transplantation; the group with the lowest survival rate the placebo group (Fig. 1).

\section{Body weight}

The results presented in Figure 2 show that treatment of the $\mathrm{SCl}$ strongly affects mean body weight. After inducing complete $\mathrm{SCl}$ in mice, mouse body weight in all the mouse groups significantly declined after the first week. However, afterwards mice in the control, placebo and allogeneic SVF transplantation groups showed similar mean body weights (no significant difference among these groups at 2, 3, 4 and 5 wks post treatment). However, mice in the autologous SVF transplantation group showed a rapid weight decline after $1 \mathrm{wk}$ of inducing $\mathrm{SCl}$, and continuously decreased from wk 2 to wk 5. In total, mice in 
this group reduced 10 grams after 5 wks, compared to before $\mathrm{SCl}$ induction and treatment (Fig. 2).

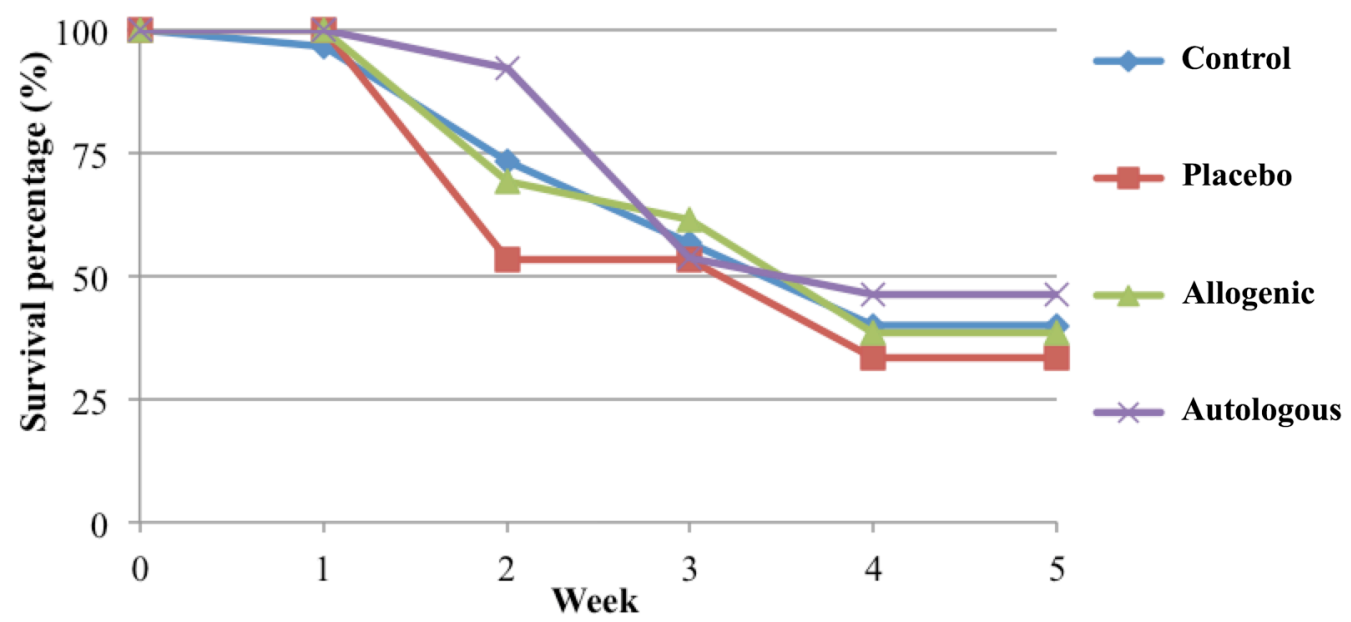

Figure 1. Survival rate of mice with $\mathbf{S C l}$ after various treatments. The survival rate of mice in the autologous SVF transplantation group was lowest. Survival rates of the control, placebo and allogeneic SVF transplantation groups were not significantly different.

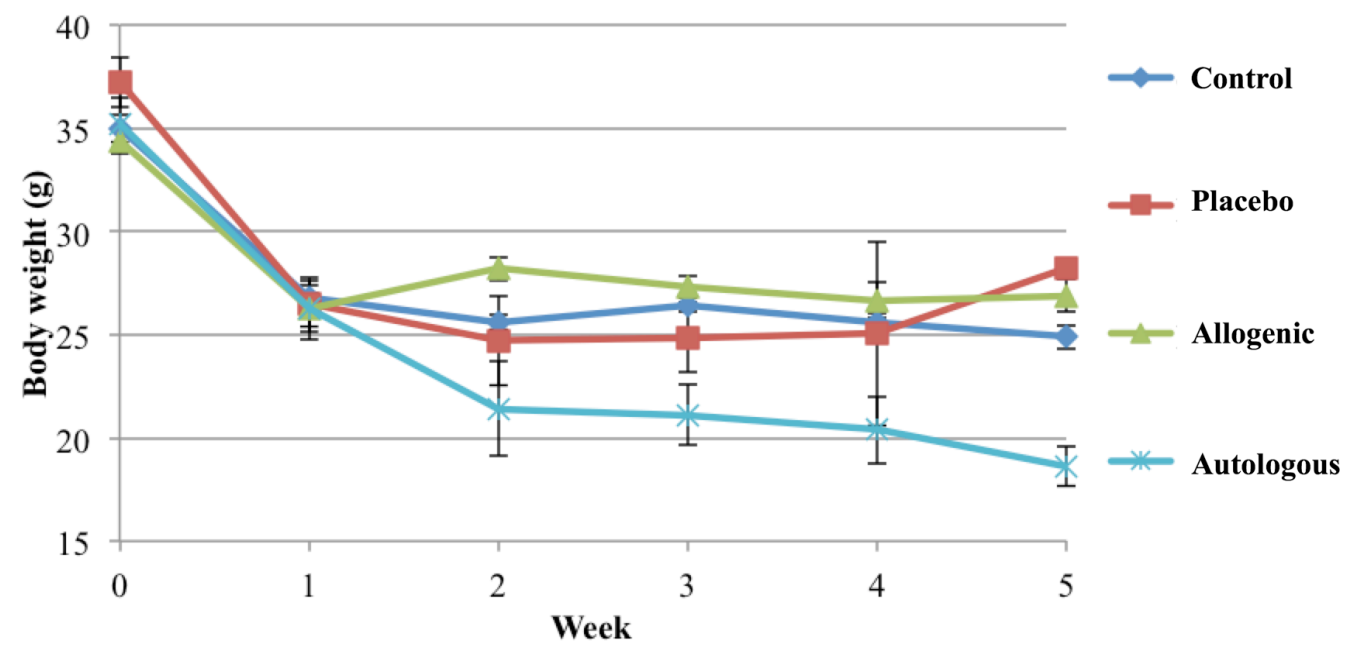

Figure 2. Mean body weight of mice after $\mathrm{SCl}$ induction and various treatments.

Mice in the autologous SVF transplantation group showed a rapid reduction in body weight over the course of 5 weeks, while mice in other groups stayed steady from week 1 to 5 . 


\section{Locomotor test}

Locomotor testing was conducted every week for 4 weeks according to the Basso, Beattie and Bresnahan (BBB) locomotor scale method (i.e. BBB score) (Basso et al., 1995; Basso et al., 1996). After 4 weeks, all mice in the control (untreated) group were completely paralyzed with score 0 on the BBB scale. The slight improvement of BBB scale was observed in the placebo and allogeneic SVF groups (Fig. 3). A significant improvement of locomotor activity was observed in the autologous SVF transplantation group compared to control and placebo $(p<0.05)$.

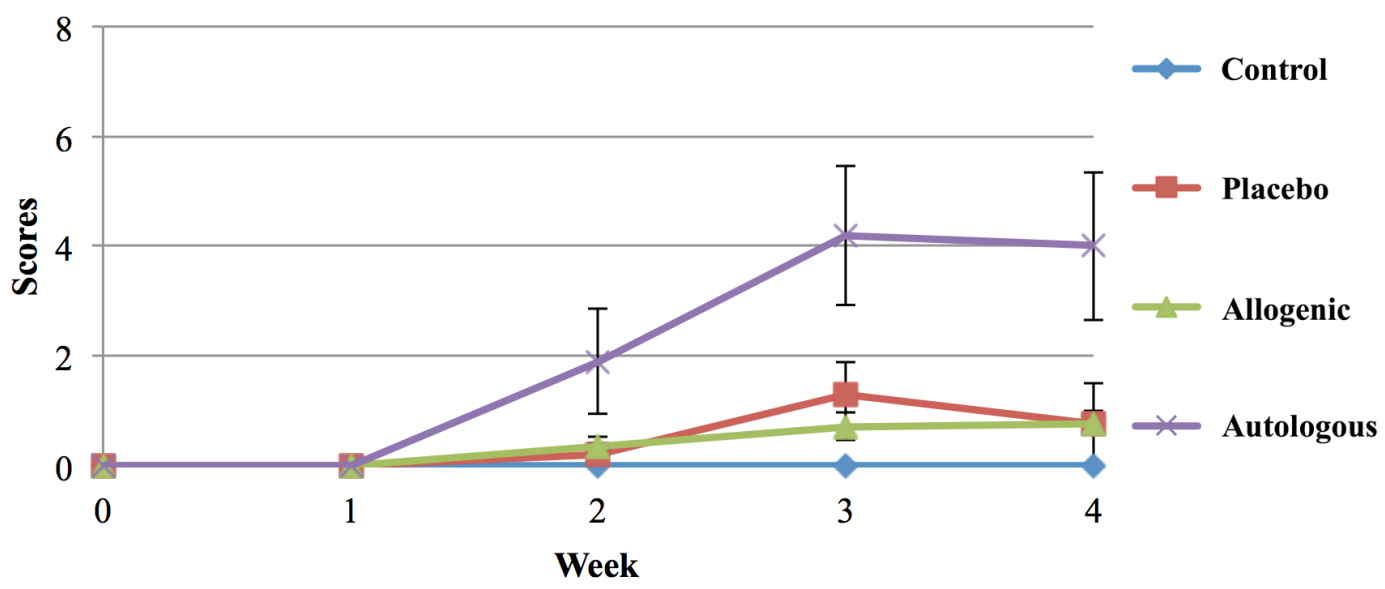

Figure 3. Locomotor score of mice with $\mathrm{SCl}$ after various treatments. Locomotor activity in allogeneic SVF-treated mice showed a significant improvement compared to the autologous SVF, control (untreated) and placebo (RPP only) treatment groups.

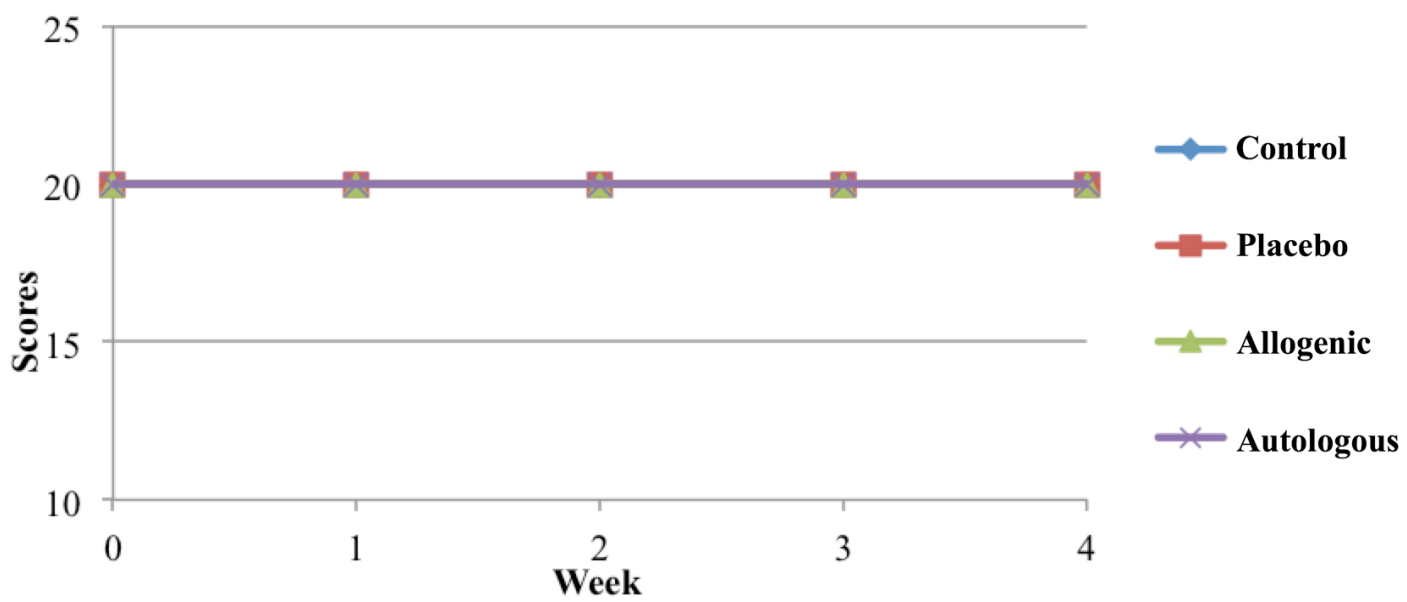

Figure 4. The results of sensory-motor testing of mice with $\mathrm{SCl}$ after various treatments. Mice in all groups could not improve their sensory-motor testing scores. 


\section{Sensory-motor testing}

To assess neural control of hind limb movement, mice were evaluated further by going on a grid. The low improvement of BBB scores suggested a low recovery of nervous control. Normally, only mice with BBB scores of 14 or more can control movement (toe stretching) (Basso et al., 1995; Santos et al., 2011). Similar to what the locomotor scores reflected in the previous results, mice in all the groups were not able to significantly recover their sensory-motor skills (Fig. 4).

\section{Total leukocytes}

In the control group, the inflammatory response normally occurs after injury of the spinal cord. Indeed, the total leukocyte count significantly increased after 3 wks. Meanwhile, for the placebo (PRP only), autologous SVF transplantation and allogeneic SVF transplantation groups, the mice showed a significant reduction of total leukocytes. From weeks 3 and 4 , the total leukocyte count in the placebo and allogeneic SVF transplantation groups increased (Fig.5), as the number of surviving mice greatly reduced (Fig. 1). This correlation suggests perhaps that one mechanism by which mouse vitality is affected is through the immune system (Fig. 5).

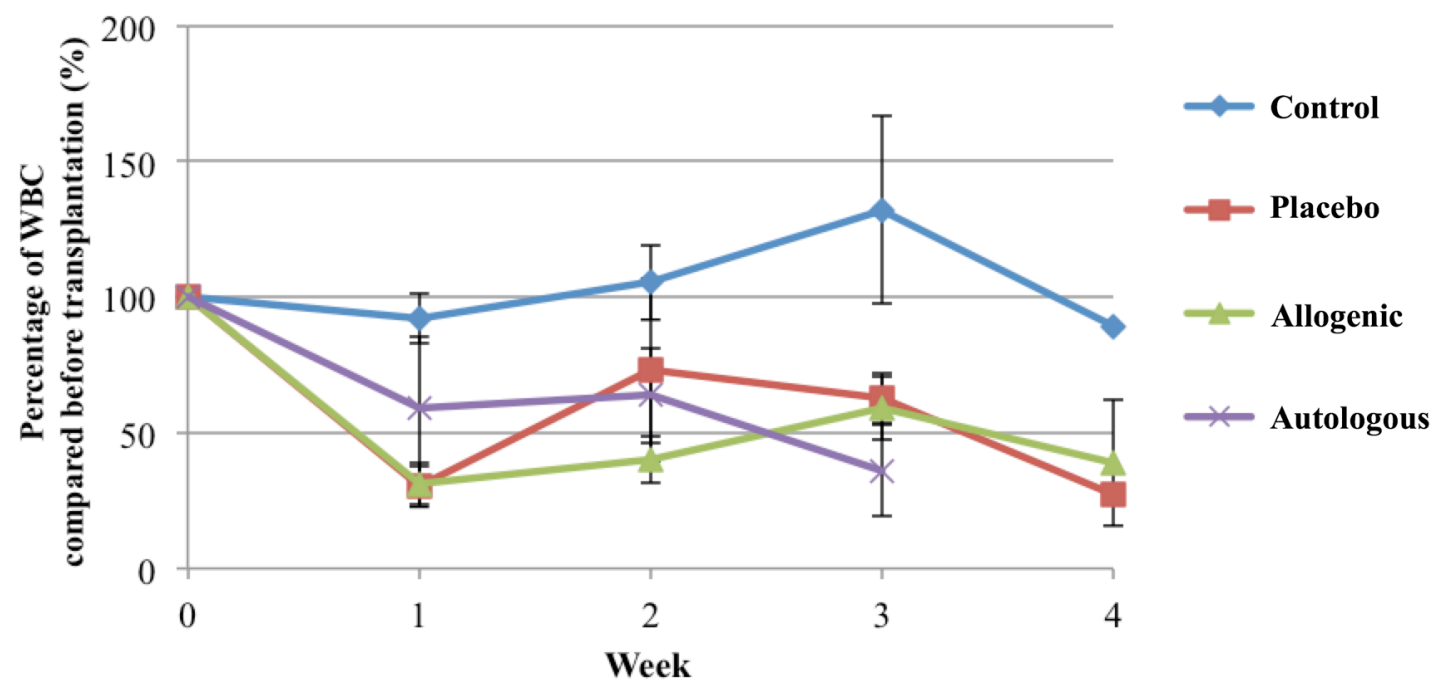

Figure 5. Change in total leukocyte count of mice with $\mathrm{SCl}$ after various treatments. The results suggest that strong inflammation is occurring in mice of the control group; however, the inflammatory process appears partly inhibited in mice of the placebo (PRP only), autologous SVF transplantation and allogeneic SVF transplantation groups. 


\section{Histological analysis}

The formation of glial scars stimulated by astrocytes has been shown to negatively affect recovery. Therefore, the inhibition of glial cell proliferation after injury can significantly improve $\mathrm{SCl}$ recovery in mice, both in movement and sensation. Histological analysis showed glial scar formation in almost all the mice, and that inflammation niches appeared after $\mathrm{SCl}$ induction and the various treatments (Fig. 6). However, for the autologous SVF transplantation mouse group, the spinal cord exhibited greater integral structure and reduced demyelination (Fig. 6). These factors can cause mice to recover partial hind limb function, but not fully.
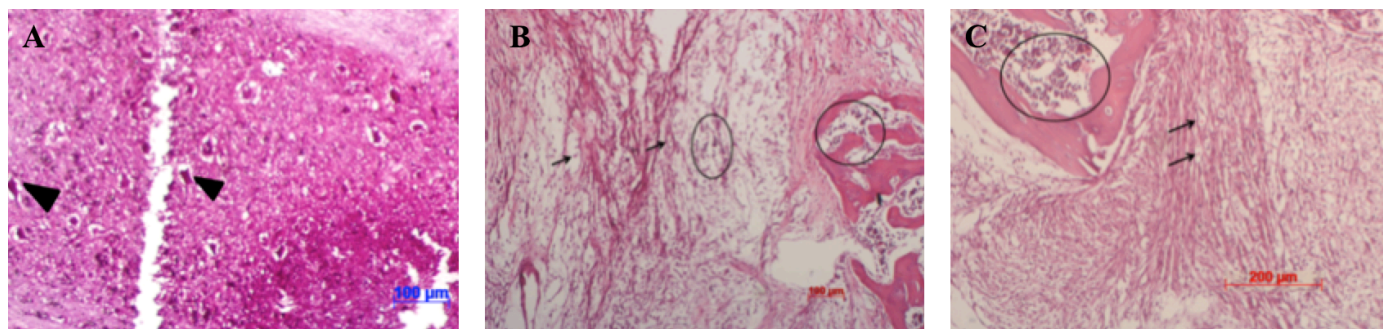

Figure 6. Damaged spinal cord tissue structures of mice with $\mathrm{SCl}$ after various treatments. The cross-sections of spinal cord tissues were analyzed in mice of the following groups: control (untreated) (A), placebo (PRP only) (B), autologous SVF transplantation (C). Arrowheads: neurons; arrows: fragments of myelin; circle: inflammation site.

\section{Detection of transplanted cells}

To determine the presence of ADSCs in grafted mice, allogeneic SVF cells from male mice were collected and transplanted into female $\mathrm{SCl}$ mice. The detection of the SRY gene in grafted spinal cord tissue was evaluated by PCR. The results showed that grafted spinal cord tissue did not express the SRY gene.

\section{Discussion}

$\mathrm{SCl}$ is an extreme injury with low regeneration potential. Therefore, almost all cases of $\mathrm{SCl}$ develop into complete paralysis. The primary aim of this study was to evaluate the effects of SVF transplantation in a mouse model of $\mathrm{SCl}$.

In the first experiment, SVFs from both autologous and allogeneic adipose tissues were extracted according to the manufacturer's recommendations. The results showed that SVFs could be successfully extracted from adipose tissues 
with a high percentage of viable cells. More importantly, the ratio of ADSCs in the SVFs was high (approximately $63.26 \pm 2.02 \%$ ).

The SVFs were evaluated as treatment for mice with $\mathrm{SCl}$. The results showed that after 5 weeks of treatment, there was a significant improvement in the autologous SVF transplantation group, in combination with PRP. The results appeared to show that PRP could cause anti-inflammation in the placebo, autologous SVF transplantation and allogeneic SVF transplantation groups. In fact, the role of PRP in inflammation control has been observed in some previous studies (Bendinelli et al., 2010; Osterman et al., 2015; Rios et al., 2015). In human chondrocytes, PRP induced anti-inflammation by NF-kB inhibition via HGF (Bendinelli et al., 2010), and via decreased expression of TIMP-1 and ADAMTS-5 in cartilage (Osterman et al., 2015).

It seems that anti-inflammation is very important to regenerate the injured spinal cord. Phil Popovich et al. (1999) injected clodronate liposomes into SCl mice and obtained the following results: a reduction in leukocyte migration to the lesion location and the hollow cavity in the cord tissue, an increase in score according to the BBB scale, a reduction in gray matter degeneration, and an increase in the number of axons and myelinated axons (Popovich et al., 1999). Decrease of leukocyte number could be a reason for the recovery.

Indeed, the secondary loss of neurons, axons and myelin were also reduced after inhibiting monocytes and neutrophils (Bao et al., 2004; Bao et al., 2005; Blight, 1994; Blight et al., 1995; Giulian and Robertson, 1990; Gris et al., 2004). Daniel et al. (2009) suggested that antibody secretion of B cells can also influence the pathology of spinal cord injury. Inflammation can also trigger glial scar formation. In fact, the formation of glial scar is stimulated by astrocytes and has been shown to negatively affect recovery (Block et al., 2007; Silver and Miller, 2004). A recent study inhibited the proliferation of glial cells after injury and showed a significant improvement of recovery in mice- both in movement and sensation (Lin et al., 2014).

In our study, total leukocyte number decreased in the three treatment groups where PRP was given (placebo, allogeneic SVF transplantation, and autologous SVF transplantation). The combination of PRP with SVFs could elicit a reduction in inflammation in mice. Moreover, the combination triggered spinal cord regeneration.

Indeed, histological analysis demonstrated that healing of the injured cord took place in mice treated with PRP. Moreover, de-methylation also decreased in those mice. Although there was no overserved complete recovery, based on assessment of mice motility and sensation, PRP had a significant impact on the total leukocyte count and spinal cord tissue structure. The total leukocyte count significantly decreased compared to non-transplanted (untreated, control) mice. Additionally, the spinal cord in PRP-treated mice showed less damage than in the control mice. 
Additionally, mice treated with PRP alone or allogeneic SVF cells have slightly improved mouse body weight (though not statistically significant). These mice do not show recovery with regards to movement, feeling or motor control ability. According to some previous studies, PRP may affect peripheral nerve regeneration. The mechanism of action of PRP could be by stimulating the regeneration of new myelination, leading to the recovered neurotransmitter capability of axons (Cho et al., 2010; Ding et al., 2009; Farrag et al., 2007). However, treatment with a single dose did not yield any clear improvement (Sariguney et al., 2008).

Our results are entirely consistent with those aforementioned and other studies. According to some recent studies (Farrag et al., 2007; Landi et al., 2011; Shen et al., 2009; Yu et al., 2011), PRP is typically used to treat a variety of neurological disorders and diseases. PRP is part of the blood system that eliminate cells and PRP contains platelets. When activated by damage, PRP will release growth factors to stimulate angiogenesis, proliferation and cell differentiation, thus inducing the formation of new areas of tissue.

In our study, compared to the other groups, the autologous SVF transplantation group showed a clear improvement in spinal cord regeneration. Spinal cord tissue in this group showed denser structures, more stroma, less glial scarring, and fewer myelin debris. Initially, we thought that immune modulation was caused by PRP as well as ADSCs inside SVFs. However, the spinal cord was clearly regenerated in this group compared to allogeneic SVF transplantation group. Therefore, the observed difference could be from the role of autologous ADSCs.

The greatest disadvantage of autologous SVF transplantation is the adverse effects of fat collection and the strong decrease of body weight. However, autologous SVF transplantation did yield the highest survival rate in mice with $\mathrm{SCl}$ and autologous SVFs could persist for a long time in mice. The grafted cells also produced paracrine factors to heal the injured site, as well as differentiate into neuronal cells. Some recent studies have showed the capability of ADSCs to differentiate into functional nervous cells, e.g. Schwann cells- to myelinate axon, both in vitro and in vivo (Anghileri et al., 2008; Chi et al., 2010; Jiang et al., 2008; Kingham et al., 2007; Krampera et al., 2007; Safford et al., 2004; Safford et al., 2002; Xu et al., 2008; Zhang et al., 2009).

In the allogeneic SVF transplantation, ADSCs only persisted at the grafted sites for a short time, and their effects on injury healing was not obvious. Evaluation of SRY expression supported this thought. After $5 \mathrm{wks}$, using sensitive PCR to evaluate SRY of male cells in the female recipients, we could not detect the expression of SRY at the grafted sites.

Our results of autologous SVF transplantation for SCI treatment are similar to the results of Sykova et al. (2006) that used bone marrow derived stem cells (Syková et al., 2006). In another study, Zaminy et al. (2013) showed better results when 
using Schwann cells; the average BBB score difference was 4 (Zaminy et al., 2013). However, Zhang et al (2009) and Chi et al. (2010) transplanted functional Schwann cells, differentiated from ADSCs, and showed that improvement was low and that there was no statistically significant difference between treatment and control groups (Chi et al., 2010; Zhang et al., 2009). The main reason was suggested to be due to the huge difference of in vitro and in vivo differentiation of stem cells to Schwann cells.

\section{Conclusion}

$\mathrm{SCl}$ is an extreme injury with low regeneration. Almost all patients with $\mathrm{SCl}$ develop completely paralysis. In this study, we produced a mouse model of $\mathrm{SCl}$ and treated them with non-expanded ADSCs (from SVFs). In combination with PRP, autologous SVF transplantation significantly improved the locomotor score in mice compared to allogeneic SVF transplantation using the same dose of SVFs. Transplantation of autologous SVF mixed with PRP decreased the number of total leukocytes, reduced glial scarring, reduced myelin defragmentation, and significant increased the BBB score. Meanwhile, SCl mice treated with PRP alone or with allogeneic SVFs mixed with PRP showed only a slight improvement of their BBB scores. This preliminary study shows that autologous SVF transplantation can be promising for $\mathrm{SCl}$ treatment.

\section{Abbreviations}

ADSC: Adipose derived stem cells; HGF: Hepatic growth factor; MSCs: Mesenchymal stem cells; PRP: Platelet rich plasma; SCl: Spinal cord injury; SVF: Stromal vascular fraction.

\section{Author Contribution}

HTML: isolated SVF from adipose tissues, transplanted SVFs to mouse models and monitoring treated mice; MNTT, KAB \& TTTL: produced the mouse models, measured some total leukocytes, histological analysis; KHTB, NKP \& PVP: performed flow cytometry, revised and corrected the manuscript, suggested the ideas for this study. 
ISSN: 2199-4633 www.cellstemcell.org

\section{References}

Anghileri, E., Marconi, S., Pignatelli, A., Cifelli, P., Galie, M., Sbarbati, A., Krampera, M., Belluzzi, O., and Bonetti, B. (2008). Neuronal differentiation potential of human adiposederived mesenchymal stem cells. Stem cells and development 17, 909-916.

Ankeny, D.P., Guan, Z., and Popovich, P.G. (2009). B cells produce pathogenic antibodies and impair recovery after spinal cord injury in mice. The Journal of clinical investigation 119, 2990-2999.

Bao, F., Chen, Y., Dekaban, G.A., and Weaver, L.C. (2004). An anti-CD11d integrin antibody reduces cyclooxygenase-2 expression and protein and DNA oxidation after spinal cord injury in rats. Journal of neurochemistry 90, 1194-1204.

Bao, F., Dekaban, G.A., and Weaver, L.C. (2005). Anti-CD11d antibody treatment reduces free radical formation and cell death in the injured spinal cord of rats. Journal of neurochemistry 94, 1361-1373.

Barros Filho, T.E.P.d., and Molina, A.E.I.S. (2008). Analysis of the sensitivity and reproducibility of the Basso, Beattie, Bresnahan (BBB) scale in Wistar rats. Clinics 63, 103-108.

Basso, D.M., Beattie, M.S., and Bresnahan, J.C. (1995). A sensitive and reliable locomotor rating scale for open field testing in rats. Journal of neurotrauma 12, 1-21.

Basso, D.M., Beattie, M.S., and Bresnahan, J.C. (1996). Graded histological and locomotor outcomes after spinal cord contusion using the NYU weight-drop device versus transection. Exp Neurol 139, 244-256.

Behrmann, D.L., Bresnahan, J.C., Beattie, M.S., and Shah, B.R. (1992). Spinal cord injury produced by consistent mechanical displacement of the cord in rats: behavioral and histologic analysis. Journal of neurotrauma 9, 197-217.

Bendinelli, P., Matteucci, E., Dogliotti, G., Corsi, M.M., Banfi, G., Maroni, P., and Desiderio, M.A. (2010). Molecular basis of anti-inflammatory action of platelet-rich plasma on human chondrocytes: mechanisms of NF-kappaB inhibition via HGF. Journal of cellular physiology 225, 757-766.

Blight, A. (1994). Effects of silica on the outcome from experimental spinal cord injury: implication of macrophages in secondary tissue damage. Neuroscience 60, 263-273.

Blight, A. (2000). Animal models of spinal cord injury. Topics in Spinal Cord Injury Rehabilitation 6, 1-13.

Blight, A.R., Cohen, T.I., Saito, K., and Heyes, M.P. (1995). Quinolinic acid accumulation and functional deficits following experimental spinal cord injury. Brain 118, 735-752.

Block, M.L., Zecca, L., and Hong, J.-S. (2007). Microglia-mediated neurotoxicity: uncovering the molecular mechanisms. Nature Reviews Neuroscience 8, 57-69.

Carballo-Molina, O.A., and Velasco, I. (2015). Hydrogels as scaffolds and delivery systems to enhance axonal regeneration after injuries. Frontiers in cellular neuroscience 9, 13.

Chi, G.F., Kim, M.-r., Kim, D.-W., Jiang, M.H., and Son, Y. (2010). Schwann cells differentiated from spheroid-forming cells of rat subcutaneous fat tissue myelinate axons in the spinal cord injury. Experimental neurology 222, 304-317.

Cho, H.H., Jang, S., Lee, S.C., Jeong, H.S., Park, J.S., Han, J.Y., Lee, K.H., and Cho, Y.B. (2010). Effect of neural-induced mesenchymal stem cells and platelet-rich plasma on facial nerve regeneration in an acute nerve injury model. The Laryngoscope 120, 907-913. 


\section{Progress in \\ STEM C E L L}

ISSN: 2199-4633 www.cellstemcell.org

Ding, X.-G., Li, S.-W., Zheng, X.-M., Hu, L.-Q., Hu, W.-L., and Luo, Y. (2009). The effect of platelet-rich plasma on cavernous nerve regeneration in a rat model. Asian journal of andrology 11, 215.

Donnelly, D.J., and Popovich, P.G. (2008). Inflammation and its role in neuroprotection, axonal regeneration and functional recovery after spinal cord injury. Experimental neurology 209, 378-388.

Farrag, T.Y., Lehar, M., Verhaegen, P., Carson, K.A., and Byrne, P.J. (2007). Effect of platelet rich plasma and fibrin sealant on facial nerve regeneration in a rat model. Laryngoscope 117, 157-165.

Gale, K., Kerasidis, H., and Wrathall, J.R. (1985). Spinal cord contusion in the rat: behavioral analysis of functional neurologic impairment. Exp Neurol 88, 123-134.

Giulian, D., and Robertson, C. (1990). Inhibition of mononuclear phagocytes reduces ischemic injury in the spinal cord. Annals of neurology 27, 33-42.

Gris, D., Marsh, D.R., Oatway, M.A., Chen, Y., Hamilton, E.F., Dekaban, G.A., and Weaver, L.C. (2004). Transient blockade of the CD11d/CD18 integrin reduces secondary damage after spinal cord injury, improving sensory, autonomic, and motor function. Journal of Neuroscience 24, 4043-4051.

Jang, S., Cho, H.-H., Cho, Y.-B., Park, J.-S., and Jeong, H.-S. (2010). Functional neural differentiation of human adipose tissue-derived stem cells using bFGF and forskolin. BMC cell biology 11, 25.

Jiang, L., Zhu, J.-K., Liu, X.-L., Xiang, P., Hu, J., and Yu, W.-H. (2008). Differentiation of rat adipose tissue-derived stem cells into Schwann-like cells in vitro. Neuroreport 19, 1015-1019.

Kingham, P.J., Kalbermatten, D.F., Mahay, D., Armstrong, S.J., Wiberg, M., and Terenghi, G. (2007). Adipose-derived stem cells differentiate into a Schwann cell phenotype and promote neurite outgrowth in vitro. Experimental neurology 207, 267-274.

Krampera, M., Marconi, S., Pasini, A., Galiè, M., Rigotti, G., Mosna, F., Tinelli, M., Lovato, L., Anghileri, E., and Andreini, A. (2007). Induction of neural-like differentiation in human mesenchymal stem cells derived from bone marrow, fat, spleen and thymus. Bone 40, 382-390.

Landi, A., Tarantino, R., Marotta, N., Ruggeri, A.G., Domenicucci, M., Giudice, L., Martini, S., Rastelli, M., Ferrazza, G., De Luca, N., et al. (2011). The use of platelet gel in postero-lateral fusion: preliminary results in a series of 14 cases. European spine journal : official publication of the European Spine Society, the European Spinal Deformity Society, and the European Section of the Cervical Spine Research Society 20 Suppl 1, S61-67.

Lin, B., Xu, Y., Zhang, B., He, Y., Yan, Y., and He, M.C. (2014). MEK inhibition reduces glial scar formation and promotes the recovery of sensorimotor function in rats following spinal cord injury. Experimental and therapeutic medicine 7, 66-72.

Macaya, D., and Spector, M. (2012). Injectable hydrogel materials for spinal cord regeneration: a review. Biomedical materials (Bristol, England) 7, 012001.

Nakagami, H., Morishita, R., Maeda, K., Kikuchi, Y., Ogihara, T., and Kaneda, Y. (2006). Adipose tissue-derived stromal cells as a novel option for regenerative cell therapy. Journal of atherosclerosis and thrombosis 13, 77-81. 


\section{Progress in \\ STEM CELL}

ISSN: 2199-4633 www.cellstemcell.org

Osterman, C., McCarthy, M.B., Cote, M.P., Beitzel, K., Bradley, J., Polkowski, G., and Mazzocca, A.D. (2015). Platelet-Rich Plasma Increases Anti-inflammatory Markers in a Human Coculture Model for Osteoarthritis. The American journal of sports medicine 43, 1474-1484.

Popovich, P.G., Guan, Z., Wei, P., Huitinga, I., van Rooijen, N., and Stokes, B.T. (1999). Depletion of hematogenous macrophages promotes partial hindlimb recovery and neuroanatomical repair after experimental spinal cord injury. Experimental neurology 158, 351-365.

Rios, D.L., Lopez, C., and Carmona, J.U. (2015). Evaluation of the anti-inflammatory effects of two platelet-rich gel supernatants in an in vitro system of cartilage inflammation. Cytokine 76, 505-513.

Safford, K., Safford, S., Gimble, J., Shetty, A., and Rice, H. (2004). Characterization of neuronal/glial differentiation of murine adipose-derived adult stromal cells. Experimental neurology 187, 319-328.

Safford, K.M., Hicok, K.C., Safford, S.D., Halvorsen, Y.-D.C., Wilkison, W.O., Gimble, J.M., and Rice, H.E. (2002). Neurogenic differentiation of murine and human adiposederived stromal cells. Biochemical and biophysical research communications 294, 371-379.

Santos, G.B.d., Cristante, A.F., Marcon, R.M., Souza, F.I.d., Barros Filho, T.E.P.d., and Damasceno, M.L. (2011). Spinal cord injury experimental model and motion evaluation protocol in Wistar rats. Acta Ortopédica Brasileira 19, 87-91.

Sariguney, Y., Yavuzer, R., Elmas, C., Yenicesu, I., Bolay, H., and Atabay, K. (2008). Effect of platelet-rich plasma on peripheral nerve regeneration. Journal of reconstructive microsurgery 24, 159-167.

Shen, Y.X., Fan, Z.H., Zhao, J.G., and Zhang, P. (2009). The application of platelet-rich plasma may be a novel treatment for central nervous system diseases. Medical hypotheses 73, 1038-1040.

Silver, J., and Miller, J.H. (2004). Regeneration beyond the glial scar. Nature Reviews Neuroscience 5, 146-156.

Straley, K.S., Foo, C.W., and Heilshorn, S.C. (2010). Biomaterial design strategies for the treatment of spinal cord injuries. Journal of neurotrauma 27, 1-19.

Syková, E., Jendelová, P., Urdzíková, L., Lesný, P., and Hejčl, A. (2006). Bone marrow stem cells and polymer hydrogels_two strategies for spinal cord injury repair. Cellular and molecular neurobiology 26, 1111-1127.

Van Pham, P., Bui, K.H.-T., Ngo, D.Q., Vu, N.B., Truong, N.H., Phan, N.L.-C., Le, D.M., Duong, T.D., Nguyen, T.D., and Le, V.T. (2013). Activated platelet-rich plasma improves adipose-derived stem cell transplantation efficiency in injured articular cartilage. Stem cell research \& therapy 4, 91.

Xu, Y., Liu, Z., Liu, L., Zhao, C., Xiong, F., Zhou, C., Li, Y., Shan, Y., Peng, F., and Zhang, C. (2008). Neurospheres from rat adipose-derived stem cells could be induced into functional Schwann cell-like cells in vitro. BMC neuroscience 9, 21.

Yu, W., Wang, J., and Yin, J. (2011). Platelet-rich plasma: a promising product for treatment of peripheral nerve regeneration after nerve injury. The International journal of neuroscience 121, 176-180.

Zaminy, A., Shokrgozar, M.A., Sadeghi, Y., Norouzian, M., Heidari, M.H., and Piryaei, A. (2013). Transplantation of schwann cells differentiated from adipose stem cells improves functional recovery in rat spinal cord injury. Archives of Iranian Medicine (AIM) 16. 
Progress in

S TE M C E L L
ISSN: 2199-4633 www.cellstemcell.org

Zhang, H.-T., Luo, J., Sui, L.-S., Ma, X., Yan, Z.-J., Lin, J.-H., Wang, Y.-S., Chen, Y.-Z., Jiang, X.-D., and Xu, R.-X. (2009). Effects of differentiated versus undifferentiated adipose tissue-derived stromal cell grafts on functional recovery after spinal cord contusion. Cellular and molecular neurobiology 29, 1283-1292. 